\title{
The Exploration of Culturally-Loaded Expressions in Translation
}

\author{
Chunhua Shen \\ School of Foreign Languages, Wuhan Polytechnic University, Wuhan, China \\ 418954792@qq.com
}

Keywords: Translation theories; Cultural-loaded words; The principles of translation

\begin{abstract}
It is very difficult to deal with the cultural-loaded expressions in translation. So it is necessary to find the principles in translating, Based on this, this paper will illustrates first the different kinds of cultural-loaded expressions, and then list the difficulties of dealing with cultural-loaded expressions, in the end, the paper gives the principles of dealing with the cultural-loaded expressions.
\end{abstract}

\section{Introduction}

Translation is a tool of intercultural communication. And every language has its own culture-loaded word terms, which are the symbolic representation of the value system, history, religion, customs, thinking patterns and life styles of peculiar culture. How to deal with the cultural-loaded expressions is a tough problem, it is necessary to find some principles of dealing with the cultural-loaded expressions in translation. That will help for people know the other culture better and lead to an effective communication.

This thesis will find some principles of dealing with the cultural-loaded expressions in translation. That will help translators to translate different works for people who want to know the other cultures and it is good for people to know the other culture well. Therefore, the study of culture-loaded words and expressions is of vital importance to cross-cultural communication.

\section{The Different Kinds of Cultural-Loaded Expressions}

Cultural Individuality Words. Language is not only just symbols and rules of the system, but also forms a process of understanding the world around us and the social environment, and we can communicate by using language. Therefore, if a thing or phenomenon does not exist in a material and social environment, the meaning of the vacancy will appear. In the process of our country's long-term historical and cultural evolution, the formation of some of our unique cultural words, we called it the allusion. As a part of the national culture, the literary allusion can reflect the cultural characteristics of a nation. It is difficult to find the corresponding culturally-loaded words in English.

Cultural Common Words. Even though the people live in different places all over the world, and has different living habit, there also have some common things that reflect people have the common thinking-pattern, just like, people are all like peace and support anti-terrorism. So, not only in Chinese but also in English, there are so many cultural common words.

Actually, some of the culturally-loaded words have overlap, and some are completely corresponding to the other type of culturally-loaded words. So when we translate this kind of word, we can take the connotation meaning and form into consideration.

Cultural Synonym. Because of the different cultures, many different words reflect the same meaning, even though they are totally different in forms and represented by different image. Many examples better reflect the difference between Chinese and English culture, because of the different living environments, there are different views on the same thing, although the image is different, but the meaning of the expression is similar. 


\section{Factors Leading to the Difficulties of Dealing with Cultural-Loaded Expressions}

The Material and Cultural Differences. The difference in material culture between the western and China is huge, which is reflected in all aspects of basic necessities of life. For example, There are some foreign words on the menu in different countries.

The Different Custom Habits. Chinese and western customs are very complex, their differences are also very numerous. As for the appellation, China is particularly complex, the title of the lineal and collateral, blood relatives and in laws elder and younger older and younger, male and female, with distant relatives such as are strict norms, one by one to distinguish.

In contrast, Western kinship appellation is relatively simple, in addition to distinguish seniority outside, closeness, inside and outside, seniority, even sex neglected. So there may be some different customs between different culture, that may also lead to some difficulties in dealing with the culturally-loaded words in translation.

The Knowledge of Different Country's History. Each story has its own background, so lack of the knowledge of different country's history, it may lead to a trouble to deal with translation. If understand the basic reasons for the formation of these differences, it helps to understand the specific performance of these differences. It is very tough to figure out the ins and outs of historical events, even if someone specializing in the study of history and culture, they may also feel difficult. So lack of the knowledge of related history is also a factor leading to the difficult to dealing with the culturally-loaded expressions.

\section{The Principles of Dealing with Culturally-Loaded Expressions}

Above all sorts of difficulties led to the cultural information is not easy to be understood and accepted by the readers who are outside the native, which requires the translator to have a keen sense of cultural consciousness and profound knowledge, and then take a bridge between the two languages. That is to say, to take appropriate translation strategies and maximize the transfer of the cultural information contained in culturally-loaded expressions, and make the source culture obtained the best embodiment in the target culture. About the principles of dealing with the culturally-loaded expressions in translation are mainly as follows:

Literal Translation or Literal Translation Plus Notes. Literal translation means "word-for-word translation", it may produce an unexpected result when dealing with the culturally-loaded expressions in translation. It not only emphasizes the unique cultural characteristics of source culture, but also make the cultural elements retained in the translation and do not cause the misunderstanding of the readers.

Transliteration or Transliteration Plus Notes. When introduce the traditional Chinese culture to others, translators always use transliteration or transliteration plus notes to deal with the culturally-loaded expressions which contains Chinese characteristics, and this way is become more and more accepted by other countries.

Free Translation. During the process of language translation, translators often encounter various obstacles due to the differences in language, which makes it easy to lose the readability of the translation. At this time, we must break the shackles of the form of language, the use of free translation to deal with the culturally-loaded expressions and enhance the readability.

Substitution. Substitution means using the words in the target language to substitute the words in the source language.

Imitation Translation Method. Imitation translation method also means calque translation, calque refers to the use of counterfeit coinage and be used to refer to new thing and new information. With the development of international exchanges, calque is playing a more and more important role in the composition of bilingual dictionaries and bilingual new vocabulary, it not only to retain the local culture, but also enrich the local language.

Creative Translation. Creative translation is a translation based on the characteristics of the 
English language and the affix. It brings new vitality to languages. So in the process of translation, on the basis of a thorough understanding of the original, creative translation is necessary, that can vividly express the spirit of the original work and thought connotation.

\section{Conclusion}

As the above listed, there are some different kinds of culturally-loaded expressions depend on different cultures. Even though the people live in different environment in the world and have their own languages, there also have some common things, then the culturally-loaded expressions can be classified as cultural individually words, cultural common words and cultural synonym. So dealing with the culturally-loaded expressions does actually exist some difficulties, such as a translator may face with the different material, custom habits and the countries' histories. At the same time, it needs to find some methods to deal with this problem. In the process of translation, in order to convey the true meaning of the culturally-loaded expressions, the translator needs to choose the appropriate translation strategies according to different situations, such as literal translation, transliteration, free translation, substitution and so on.

\section{References}

[1] Andrew Skuse. Drama for Development: Cultural Translation and Social Change [J]. SAGE Publications Pvt. Ltd, 2011.

[2] Bassnett, S. \& A. Lefecere(eds.). (1990). Translation, History and Culture [J]. London\&New York: Printer, 1990.

[3] Birgit Mersmann, Alexandra Schneider. Transmission Image: Visual Translation and Cultural Agency [M]. Cambridge Scholars Publishing, 2009.

[4] Micaela Munoz-Calvo, Carmen Buesa-Gomez, M Angeles Ruiz-Moneva. New Trends in Translation and Cultural Identity [M]. Cambridge Scholars Publishing, 2008.

[5] Maurice Friedberg. Literary Translation in Russia: A Cultural History [M]. Pennsylvania a State University Press, 2008.

[6] Nida, E. A. Language, Culture, and Translating [M]. Shanghai Foreign Language Education Press, 1993.

[7] Peter Burke, R. Po-chiaHsia. Cultural Translation in Early Modern Europe [M]. Cambridge University Press, 2009.

[8] Paperback. Asia through Art and Anthropology: Cultural Translation Across Borders [M]. Bloomsbury Academic, 2013.

[9] Stephen Kelly, David Johnston. Betwixt and Between: Place and Cultural Translation [M]. Cambridge Scholars Press, 2007.

[10] Stephen J. Campbell, Stephen J. Milner. Artistic Exchange and Cultural Translation in the past [M]. Cambridge University Press, 2004. 